\title{
Mixing Design for ATIG Morphology and Microstructure Study of 316L Stainless Steel
}

\author{
Kamel Touileb \\ Mechanical Engineering Department, \\ College of Engineering, Prince Sattam \\ Bin Abdulaziz University, \\ Al Kharj, Saudi Arabia \\ k.touileb@psau.edu.sa
}

\author{
Abdejlil Hedhibi \\ Mechanical Engineering Department, \\ College of Engineering, Prince Sattam \\ Bin Abdulaziz University, \\ Al Kharj, Saudi Arabia \\ a.hedhibi@psau.edu
}

\author{
Rachid Djoudjou \\ Mechanical Engineering Department, \\ College of Engineering, Prince Sattam \\ Bin Abdulaziz University, \\ Al Kharj, Saudi Arabia \\ r.djoudjou@psau.edu.sa
}

\author{
Abousoufiane Ouis \\ Mechanical Engineering Department, \\ College of Engineering, Prince Sattam Bin Abdulaziz \\ University, Al Kharj, Saudi Arabia \\ a.ouis@psau.edu.sa
}

\author{
Mohamed Lamjed Bouazizi \\ Mechanical Engineering Department, \\ College of Engineering, Prince Sattam Bin Abdulaziz \\ University, Al Kharj, Saudi Arabia \\ my.bouazizi@psau.edu.sa
}

\begin{abstract}
This work is a study of the effects of oxides combination on the morphology of $316 \mathrm{~L}$ stainless steel welds. A series of thirteen weld lines were carried out using thirteen different oxides. Based on the depth and ratio $\mathrm{D} / \mathrm{W}$ results, three candidate oxides were selected: $\mathrm{Ti}_{2} \mathrm{O}, \mathrm{Mn}_{2} \mathrm{O}_{3}$, and $\mathrm{SiO}_{2}$. Mixing method available in Minitab 17 software is the most appropriate method to find the optimal combinations to get the best depth and $\mathrm{D} / \mathrm{W}$ ratio. According to simplex lattice degree four, nineteen combinations of these oxides were prepared. The results show that the optimal composition of flux was: $66 \% \mathrm{SiO}_{2}-34 \% \mathrm{Mn}_{2} \mathrm{O}_{3}$. The depth and $\mathrm{D} / \mathrm{W}$ ratio increased to $8.85 \mathrm{~mm}$ and 0.98 respectively for optimal ATIG, whereas for the conventional TIG welding, the depth and the ratio $\mathrm{D} / \mathrm{W}$ didn't exceed $1.65 \mathrm{~mm}$ and 0.17 respectively. For TIG weld joint the hardness is about 47 HRA and it increases to 77 HRA for the optimal ATIG weld joint. The absorbed energies in Charpy impact test are 146 and $138 \mathrm{~kJ}$ in the weld zone and in the heat affected zone respectively for the TIG welding and they dropped to 111 and $74 \mathrm{~kJ}$ for the optimal ATIG welding. The fracture surface examined by scanning electron microscope (SEM) shows a ductile fracture for TIG weld with small dimples but ductile-brittle fracture for ATIG weld. Energy dispersive spectroscopy (EDS/SEM) analysis shows the formation of $\mathrm{FeS}_{2}$ and $\mathrm{SiO}_{2}$ in the weld zone causing low absorbed energy for ATIG weld.
\end{abstract}

Keywords-ATIG; 316L austenitic stainless steel; ATIG welding mixing method; ternary flux

\section{INTRODUCTION}

TIG welding process is quite widespread. However, weld penetration varies from cast to cast and the maximum weld depth in a single pass does not exceed $3 \mathrm{~mm}$. Activated TIG (ATIG) welding proposed by Paton Institute-Kiev [1,2] seems an appropriate process to overcome these weaknesses. ATIG welding uses the same equipment as TIG except a prior weld operation layer of activated flux paste is deposited on the workpiece. Hypotheses have been made to explain the phenomenon favoring a high weld depth. Authors in [3-6] proposed that the Marangoni convection is the most important factor in determining weld shape. Surfactant elements as S, Se, $\mathrm{Te}, \mathrm{O}$ in weld pool affect the convection of molten metal leading to centripetal circulation of weld metal getting a depth of weld. Authors in [7, 8] applied the principle of electron absorption [9], electronegative elements as halides (fluorine) migrate to arc weld and capture outer arc electrons which contribute to contract the arc welding. This phenomenon increases the density of arc welding and the heat provided to weld pool. Authors in [10-12] proposed that high electrical resistance of flux components contributes to arc constriction. Many works were subsequently carried out using oxides like $\mathrm{SiO}_{2}, \mathrm{TiO}_{2}, \mathrm{Cr}_{2} \mathrm{O}_{3}, \mathrm{Fe}_{2} \mathrm{O}_{3}, \mathrm{CaO}, \mathrm{ZrO}_{2}, \mathrm{MgO}$ [13-24], chlorides [25-27], and fluorides [28, 29] to improve weld depth. These studies showed an increasing in the weld depth without affecting the mechanical properties of the specimens [30, 31]. Other studies were dedicated to microstructure and mechanical properties [32-33]. In this work, 13 oxides were investigated on 316L austenitic stainless steel. Design of experiments was used to predict the best combination of the tested oxides. Mixing method based on a simplex lattice degree four was the key tool to optimize the flux combination in order to enhance the depth and $\mathrm{D} / \mathrm{W}$ ratio.

\section{EXPERIMENTAL PROCEDURE}

\section{A. Materials}

The material used was the $316 \mathrm{~L}$ stainless steel whose chemical composition is shown in Table I. Experiments consisted of welding a $20 \mathrm{~cm}$ line on a rectangular plate of $6 \mathrm{~mm}$ thickness. Before welding, the plates were cleaned with acetone. Flux powders were dried in furnace to eliminate humidity, and then mixed with methanol in 1:1 ratio. A flux

Corresponding author: Kamel Touileb 
layer less than $0.2 \mathrm{~mm}$ thick was deposited on the surface to be welded.

\section{TABLE I. $\quad$ 316L CHEMICAL COMPOSISTION}

\begin{tabular}{|c|c|}
\hline Element & Percentage (\%) \\
\hline $\mathrm{C}$ & 0.018 \\
\hline $\mathrm{Mn}$ & 1.30 \\
\hline $\mathrm{Si}$ & 0.43 \\
\hline $\mathrm{P}$ & 0.034 \\
\hline $\mathrm{S}$ & 0.0029 \\
\hline $\mathrm{Cr}$ & 16.78 \\
\hline $\mathrm{Ni}$ & 10.00 \\
\hline $\mathrm{Mo}$ & 2005 \\
\hline $\mathrm{Ti}$ & 0.0042 \\
\hline $\mathrm{Cu}$ & 0.2082 \\
\hline $\mathrm{Co}$ & 0.226 \\
\hline $\mathrm{N}(\mathrm{ppm})$ & 321 \\
\hline
\end{tabular}

\section{B. Welding Procedure}

A Tungsten Inert Gas welding machine was used. A watercooled torch with a standard $2 \%$ thoriated tungsten electrode rod having diameter of $3.2 \mathrm{~mm}$ has been used for the experiments. The torch was mounted on a motorized carriage as shown in Figure 1. A series of tests were carried out with $150 \mathrm{~A}$ welding current and $15 \mathrm{~cm} / \mathrm{min}$ welding speed leading to a provided energy of $540 \mathrm{~kJ} / \mathrm{m}$. The welding parameters for the TIG welding are listed in Table II.

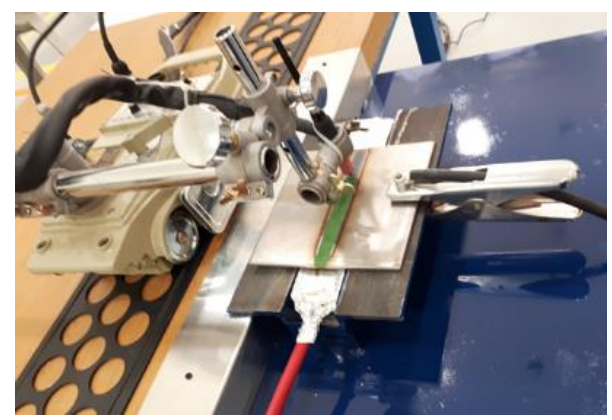

Fig. 1. Experimental setup of TIG welding with flux paste (a motorized carriage, torch-workpiece).

TABLE II. WELDING PARAMETERS

\begin{tabular}{|c|c|}
\hline Welding speed & $15 \mathrm{~cm} / \mathrm{min}$ \\
\hline Welding current & $150 \mathrm{~A}$ \\
\hline Arc length & $2 \mathrm{~mm}$ \\
\hline Electrode Tip Angle & $45^{\circ}$ \\
\hline Shield gas on work piece & Argon with flow rate $121 / \mathrm{min}$ \\
\hline Shield gas back side & Argon with flow rate $51 / \mathrm{min}$ \\
\hline Welding mode & Direct current electrode negative \\
\hline
\end{tabular}

\section{Mechanical Testing}

After welding, the samples were cut as shown in Figure 2 to acquire test samples for mechanical testing and weld morphology. The Rockwell hardness measurement was performed with a Digital Hardness Tester Model HRS-150. The hardness tests were conducted in the bulk of weld bead, and the results were the average of four indentations as shown in Figure 3.

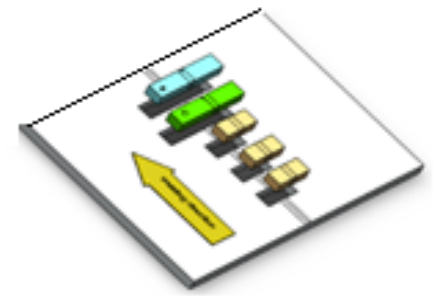

Fig. 2. Different test specimens on welded TIG and ATIG plate

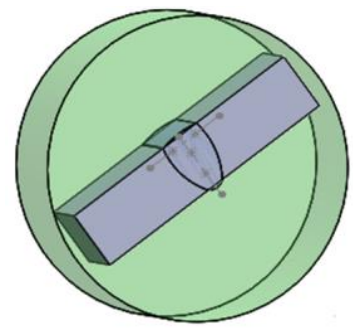

Fig. 3. Hardness test locations on weld bead

Impact tests were carried out with the impact testing machine model JBS-500. The specimens were cut according to ASTM E23 and the impact tests were conducted in the weld bead and in the HAZ as shown in Figure 4.

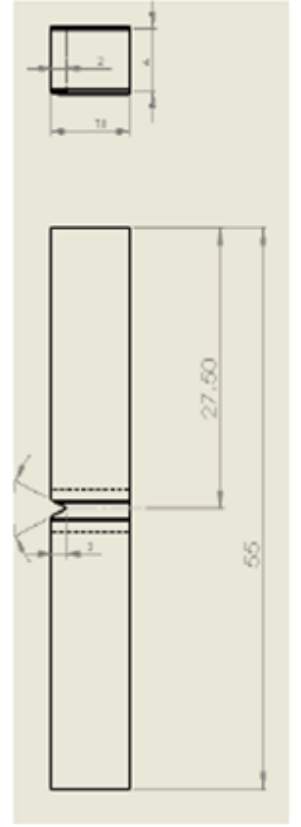

(a)

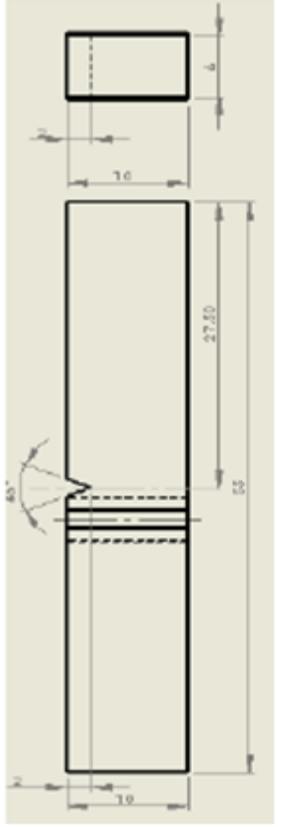

(b)
Fig. 4. Test specimen for impact test (a) weld zone, (b) HAZ

\section{Experiment by Mixing Method Design (DOE)}

For the DOE, mixing method in mini tab 17 was applied and consequently the number of experiments to be conducted was reduced. In order to compare the effect of the flux on the tensile strength, 13 oxides $\left(\mathrm{SiO}_{2}, \mathrm{TiO}_{2}, \mathrm{Fe}_{2} \mathrm{O}_{3}, \mathrm{Cr}_{2} \mathrm{O}_{3}, \mathrm{ZnO}\right.$, $\mathrm{ZrO}_{2}, \mathrm{CaO}, \mathrm{Mn}_{2} \mathrm{O}_{3}, \mathrm{~V}_{2} \mathrm{O}_{5}, \mathrm{MoO}_{3}, \mathrm{SrO}_{2}, \mathrm{CoO}_{3}$, and $\mathrm{MgO}$ ) were 
tested. Among these oxides, 3 gave the best depth and D/W ratio and were selected to be used in the mixing design method. Based on the simplex lattice degree four designs, 19 combinations have been selected. Nineteen weld lines were executed and samples for morphology, hardness and impact tests were cut. The optimizer module available in mini tab 17 was used to get the optimal formulation of flux which is expected to give the best depth and D/W ratio of weld. Finally, using the optimal formulation, ATIG weld line has been carried out along with another weld line without flux (TIG).

\section{RESULTS AND DISCUSSION}

\section{A. Depth D and D/W Ratio}

Figure 5 shows the weld depth results of ATIG weldment of the tested preliminary 14 oxides. The highest value of depth is $6.04 \mathrm{~mm}$ which is obtained for the sample welded with $\mathrm{Mn}_{2} \mathrm{O}_{3}$ flux, followed by the sample welded with $\mathrm{SiO}_{2}$ flux $(5.29 \mathrm{~mm})$, and then by the sample welded with $\mathrm{TiO}_{2}(4.81 \mathrm{~mm})$. So the oxides $\mathrm{Mn}_{2} \mathrm{O}_{3}, \mathrm{SiO}_{2}$, and $\mathrm{TiO}_{2}$ were selected. The results of the depth and D/W ratio for different proportions of the 3 selected oxides are shown in Table III.

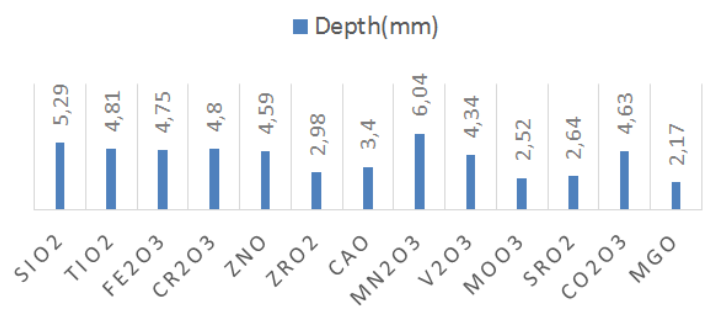

Fig. 5. Depth of ATIG welds.

TABLE III. DIFFERENT COMPOSITIONS OF FLUXES, DEPTH AND D/W

\begin{tabular}{|c|c|c|c|c|c|}
\hline Exp. No. & $\mathbf{S i O}_{\mathbf{2}} \%$ & $\mathbf{T i O}_{\mathbf{2}} \%$ & $\mathbf{M n}_{\mathbf{2}} \mathbf{O}_{\mathbf{3}} \%$ & Depth (mm) & D/W \\
\hline 1 & 75 & 25 & 0 & 4.23 & 0.54 \\
\hline 2 & 75 & 0 & 25 & 6.72 & 0.92 \\
\hline 3 & 0 & 75 & 25 & 4.47 & 0.58 \\
\hline 4 & 25 & 75 & 0 & 4.61 & 0.61 \\
\hline 5 & 25 & 0 & 75 & 3.77 & 0.49 \\
\hline 6 & 0 & 25 & 75 & 3.95 & 0.53 \\
\hline 7 & 0 & 50 & 50 & 5.66 & 0.77 \\
\hline 8 & 50 & 0 & 50 & 6.63 & 0.90 \\
\hline 9 & 50 & 50 & 0 & 6.36 & 0.83 \\
\hline 10 & 50 & 25 & 25 & 6.66 & 0.86 \\
\hline 11 & 25 & 50 & 25 & 4.85 & 0.63 \\
\hline 12 & 25 & 25 & 50 & 3.48 & 0.43 \\
\hline 13 & 33.3 & 33.3 & 33.3 & 4.93 & 0.66 \\
\hline 14 & 66.67 & 16.67 & 16.67 & 5.01 & 0.72 \\
\hline 15 & 16.67 & 66.67 & 16.67 & 5.27 & 0.72 \\
\hline 16 & 16.67 & 16.67 & 66.67 & 4.70 & 0.64 \\
\hline 17 & 100 & 0 & 0 & 5.29 & 0.74 \\
\hline 18 & 0 & 100 & 0 & 4.81 & 0.66 \\
\hline 19 & 0 & 0 & 100 & 6.04 & 0.82 \\
\hline
\end{tabular}

\section{B. Mixture Contour Plot}

Mixture contour plots for depth D and D/W were generated using Minitab software and are shown in Figure 6. The isocontour lines and the regions confined between them indicate different levels of depth or D/W. Different colors represent the different levels of the two properties. The interesting zone lies where the values of depth and D/W were higher. Optimizer module available in Minitab was used to predict the responses of depth and D/W ratio. The composite desirability is equal to 1 $(100 \%)$. It indicates that the parameters achieve favorable results for all responses, which means that both responses are within acceptable limits, as shown in Figure7. The predicted values are listed in Table IV. The optimal combination of flux is represented in Table V.

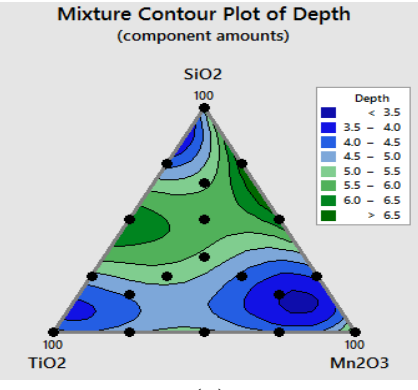

(a)

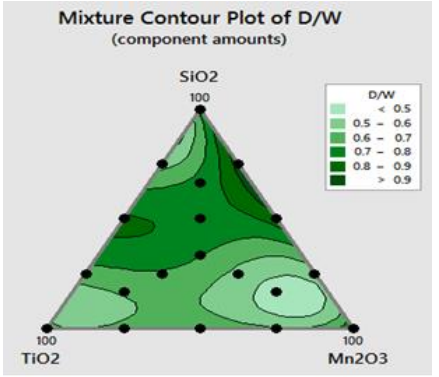

(b)
Fig. 6. Mixture contour of plot for (a) Depth and (b) D/W ratio.

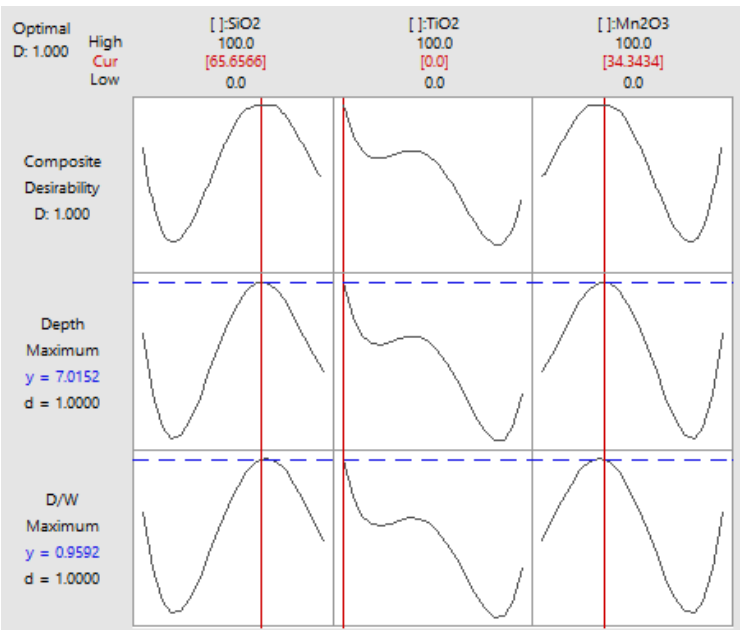

Fig. 7. Optimization plot

TABLE IV. PREDICTED RESPONSES (UTS, HRA) OF WELD EXECUTED WITH OPTIMAL FLUX

\begin{tabular}{|c|c|c|}
\hline Responses & Predicted responses & Desirability \\
\hline Depth(mm) & 7.01 & $100 \%$ \\
\hline D/W & 0.96 & $100 \%$ \\
\hline
\end{tabular}

TABLE V. OPTIMAL COMPOSITION OF FLUX.

\begin{tabular}{|c|c|c|c|}
\hline variables & $\mathrm{SiO}_{2}$ & $\mathrm{TiO}_{2}$ & $\mathrm{Mn}_{2} \mathrm{O}_{3}$ \\
\hline \multirow{2}{*}{ Percentage (\%)s } & 66 & 0 & 34 \\
\cline { 2 - 4 } & \multicolumn{3}{|c}{100} \\
\hline
\end{tabular}

\section{Confirmation Test}

The confirmation test is the last step in the experimental process. Confirmation tests were conducted based on the optimum flux composition obtained in the mixing design method of Minitab. The experimental values of depth and D/W ratio of the optimal flux ATIG weld are reported in Table VI. 
The results show the depth of optimized flux is greater than TIG weld by 5 times. The ratio D/W improved 6 times. The experimental values obtained for depth in ATIG and TIG welds are shown in Figure 8. The penetration weld of optimized flux $(8.85 \mathrm{~mm})$ is greater than the maximum value predicted by the software $(7.01 \mathrm{~mm})$. Furthermore, the $\mathrm{D} / \mathrm{W}$ value obtained for ATIG weld (0.98) is very close to the maximum predicted value of 0.96 as shown in Figure 9. TIG molten metal behaves as pure metal with centrifugal convection leading to wide and sallow weld bead contrariwise. ATIG weld metal has a centripetal movement related to oxygen liberated from oxides during welding operation. The quantity of liquid melted in ATIG $\left(51.51 \mathrm{~mm}^{2}\right)$ is higher than in TIG weld bead $\left(14.2 \mathrm{~mm}^{2}\right)$ as shown in Figures10-11.

TABLE VI. MORPHOLOGY OF TIG AND ATIG WELDS

\begin{tabular}{|c|c|c|}
\hline & ATIG(with optimal flux) & TIG \\
\hline Depth(mm) & 8.85 & 1.65 \\
\hline W(mm) & 9.04 & 9.92 \\
\hline D/W & 0.98 & 0.17 \\
\hline
\end{tabular}

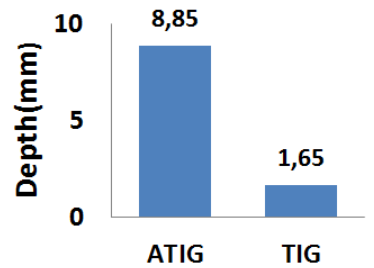

Fig. 8. Depths of ATIG and TIG welds

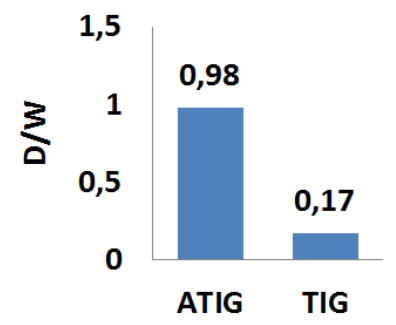

Fig. 9. D/W of ATIG and TIG welds

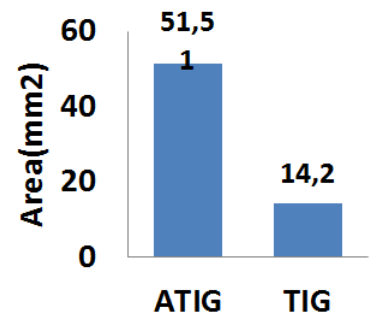

Fig. 10. Areas of ATIG and TIG welds

\section{Hardness Test}

The experimental values obtained for hardness are shown in Figure 12. ATIG hardness number of HRA $=77$ is greater than TIG hardness number of HRA=47.

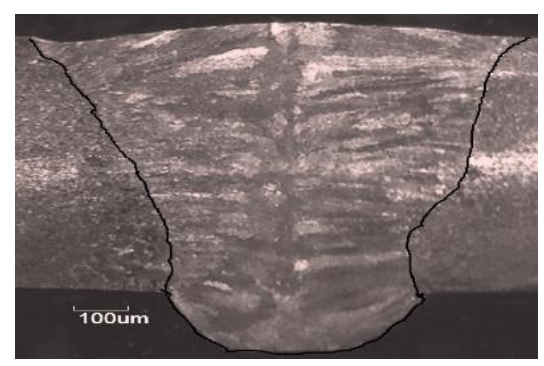

(b)

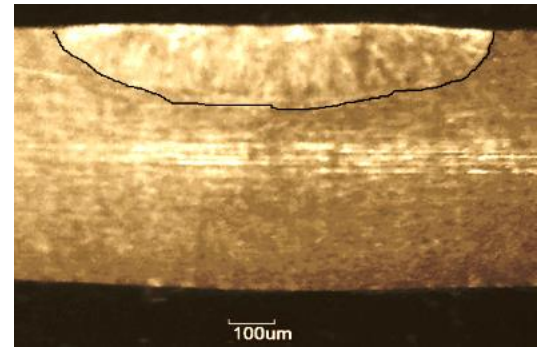

Fig. 11. Morphology of (a) ATIG and (b) TIG welds

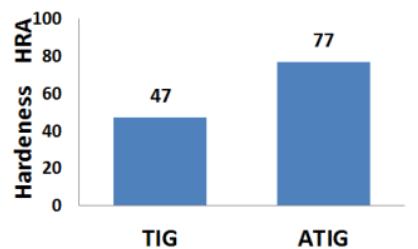

Fig. 12. Hardness HRA in weld zone for ATIG and TIG welds.

\section{E. Impact Test}

The experimental values obtained from the impact test are shown in Figures 13-14.

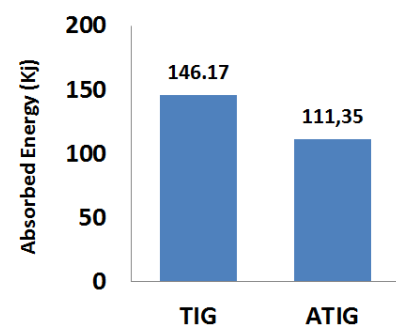

Fig. 13. Absorbed energy in weld zone for TIG and ATIG welds.

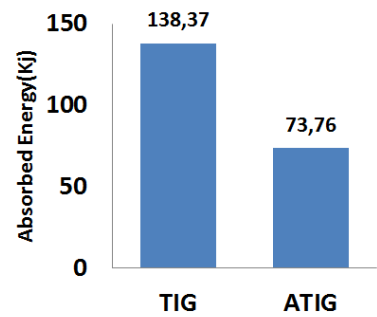

Fig. 14. Absorbed energy in HAZ for TIG and ATIG welds.

The energies absorbed either in the weld zones or in HAZ of TIG welds are higher than the ones of ATIG welds. Figure 15 shows the images of fractograph of the "V" notch Charpy 
impact test conducted on scanning electronic microscope (SEM). The images show the formation of micro-voids, with multiple dimples which demonstrate that the fracture is in ductile mode in the cases of TIG weld zone (a) and in TIG heat affected zone (c). Combined ductile (small colonies with finer dimples) and brittle fracture mode formation characterizes the ATIG weld zone (b) and the ATIG affected zone (d). The combined ductile and brittle fracture mode leads to poor resistance to sudden impact loads.

(a) TIG welded zone (500X)

(b) ATIG welded zone (500X)

(c) TIG heat affected zone $(500 \mathrm{X})$

(d) ATIG heat affected zone $(500 \mathrm{X})$
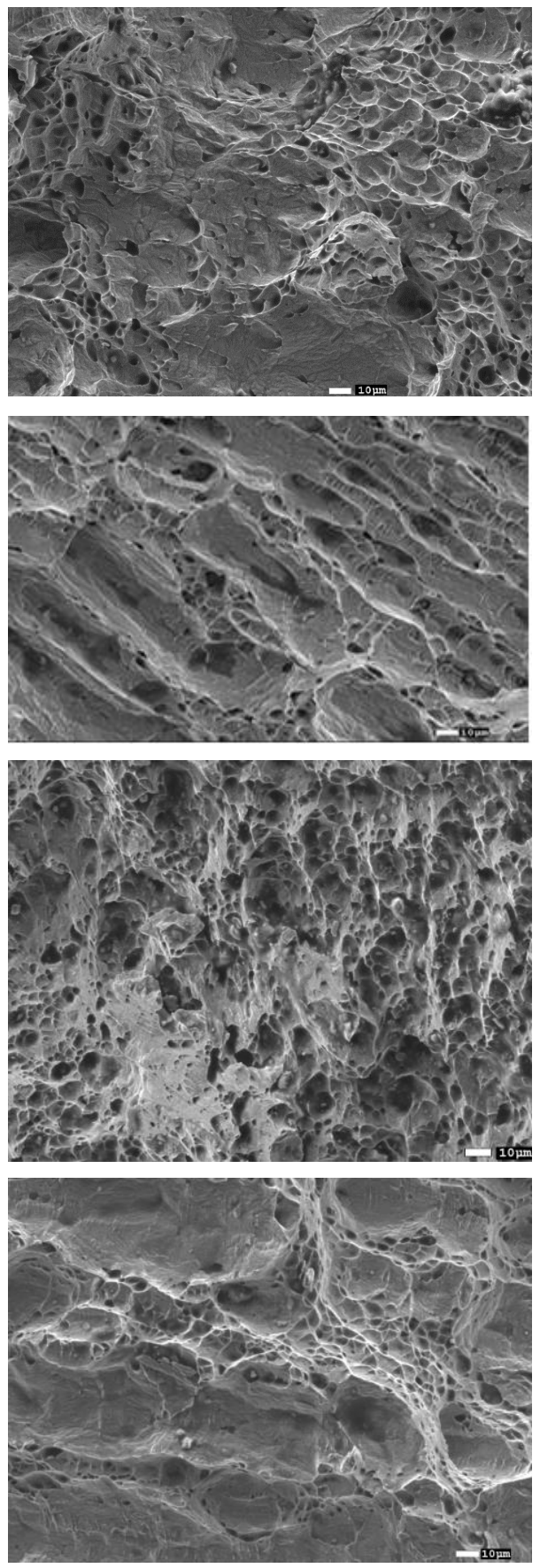

Fig. 15. Fractograph of SS 316L impact charpy "V" notch

\section{F. Microstructure Study}

Microstructure study was performed in order to view the material properties after the welding in both TIG and ATIG weldings.

\section{1) EDS/SEM Analysis}

The results of EDS/SEM analysis in Figures 16 and 17 show the presence of silicon, sulphur and oxygen in ATIG weld bead and in the heat affected zone, that lead to formations of inclusions as $\mathrm{FeS}_{2}$. Moreover, oxygen initiates microvoids and propagates by micro void coalescence, which facilitate the fracture phenomenon. These results can explain the low impact resistance in ATIG weld. The results of EDS/SEM analysis in Figures 18 and 19 show the presence of silicon in TIG weld zone in quantities close to the quantity in the received plate. The weld zone and the HAZ are free from oxygen and sulphur which can explain the withstanding of TIG weld to sudden impact. The results obtained with EDS/SEM regarding TIG weld may explain the high resistance to impact test.

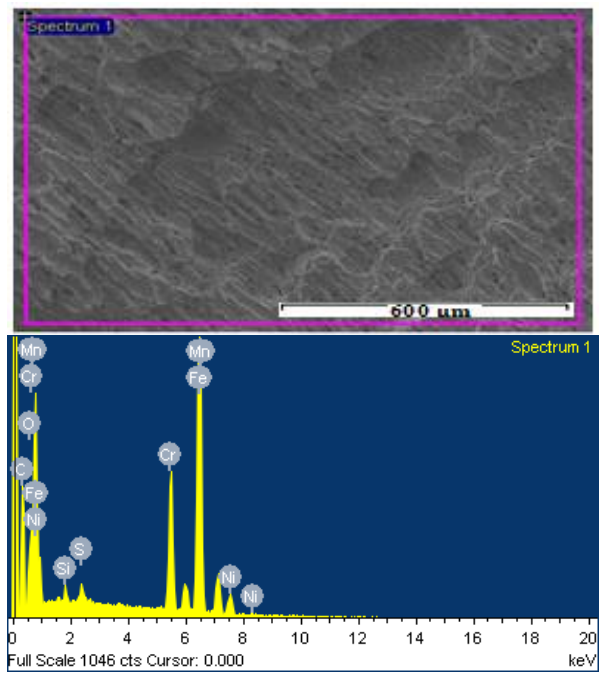

Fig. 16. EDS/SEM spectrum analysis of fracture face of ATIG welded zone

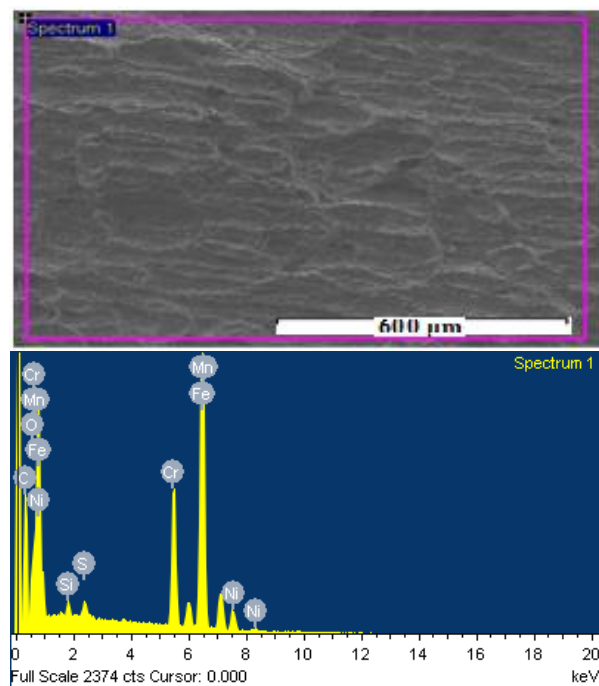

Fig. 17. EDS/SEM spectrum analysis of fracture face of ATIG HAZ 
TABLE VII. ELEMENTS PRESENT IN FRACTURE FACE OF ATIG WELDED ZONE

\begin{tabular}{|c|c|c|c|c|c|c|c|c|}
\hline Element & $\mathbf{C}$ & $\mathbf{S i}$ & $\mathbf{C r}$ & $\mathbf{M n}$ & $\mathbf{F e}$ & $\mathbf{N i}$ & $\mathbf{O}$ & $\mathbf{S}$ \\
\hline Weight $\%$ & 20.50 & 0.51 & 14.43 & 1.98 & 53.44 & 6.41 & 2.29 & 0.43 \\
\hline
\end{tabular}

TABLE VIII. ELEMENTS PRESENT IN FRACTURE FACE OF ATIG HAZ

\begin{tabular}{|c|c|c|c|c|c|c|c|c|}
\hline Element & $\mathbf{C}$ & $\mathbf{S i}$ & $\mathbf{C r}$ & $\mathbf{M n}$ & $\mathbf{F e}$ & $\mathbf{N i}$ & $\mathbf{O}$ & $\mathbf{S}$ \\
\hline Weight \% & 21.17 & 0.56 & 14.57 & 1.43 & 52.93 & 6.57 & 2.36 & 0.42 \\
\hline
\end{tabular}

The results of EDS/SEM analysis in Figures 18 and 19 show the presence of silicon in TIG weld zone. The weld zone and the HAZ are free from oxygen and sulphur which can explain the widstand of TIG weld to sudden impact. The results obtained with EDS/SEM regarding TIG weld may explain the high resistance to impact test.
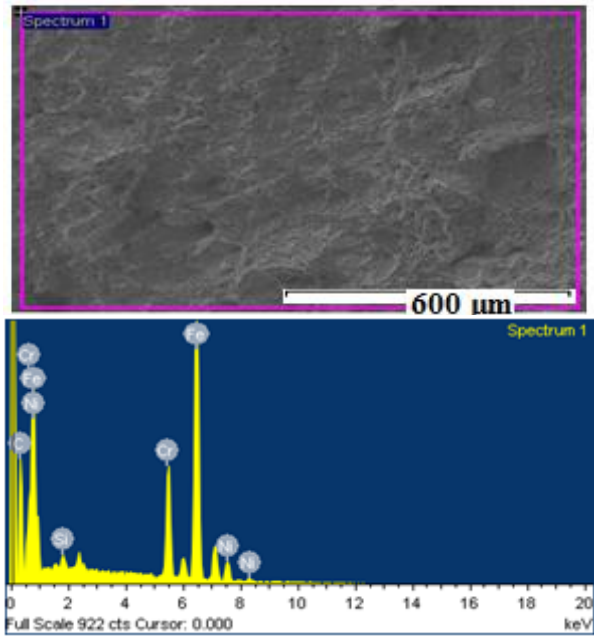

Fig. 18. EDS/SEM spectrum analysis of fracture face of TIG welded zone

TABLE IX. ELEMENTS PRESENT IN FRACTURE FACE OF TIG WELDED ZONE

\begin{tabular}{|c|c|c|c|c|c|}
\hline Element & $\mathbf{C}$ & $\mathbf{S i}$ & $\mathbf{C r}$ & $\mathbf{F e}$ & $\mathbf{N i}$ \\
\hline Weight $\%$ & 21.23 & 0.48 & 14.52 & 56.32 & 7.44 \\
\hline
\end{tabular}

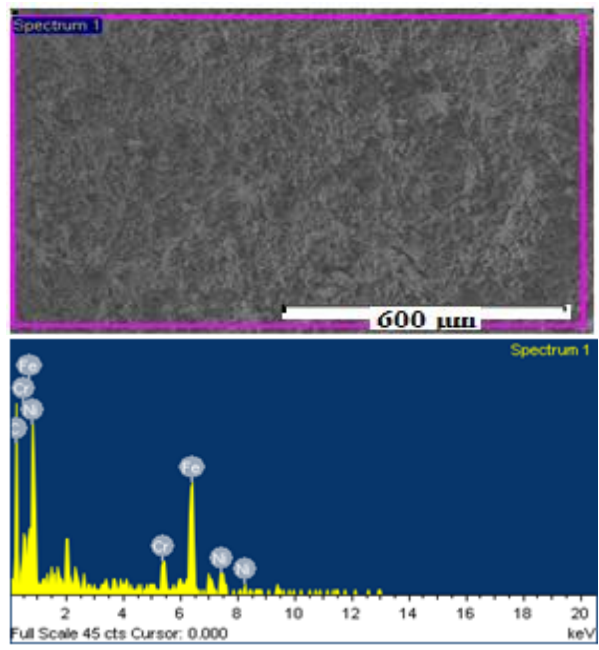

Fig. 19. EDS/SEM spectrum analysis of fracture face of TIG HAZ
TABLE X. ELEMENTS PRESENT IN FRACTURE FACE OF TIG HAZ

\begin{tabular}{|c|c|c|c|c|}
\hline Element & $\mathbf{C}$ & $\mathbf{C r}$ & $\mathbf{F e}$ & $\mathbf{~ N i}$ \\
\hline Weight $\%$ & 44.04 & 7.06 & 36.10 & 12.81 \\
\hline
\end{tabular}

\section{2) Ferrite Proportions}

The measurement of ferrite content in the austenite matrix was conducted using area image processing software of Microvision Instruments. The weld zone appearance of ATIG and TIG was examined by SEM. The measurements were taken in 4 different locations in the weld zone and the results were the average of these measurements. Delta ferrite morphology has a vermicular network structure in both ATIG and TIG welds as shown in Figure 20. Results show ferrite content equal to $10.4 \%$ for ATIG. Instead, there is a decrease in ferrite content to $6.8 \%$ for TIG. This can be explained by the fact that in the case of ATIG operation, the weld bead is fully penetrated with a large weld bead area up to $55 \mathrm{~mm}^{2}$. During ATIG weld operation, the activated flux has a beneficial effect in increasing the heat provided to weld pool and consequently the peak temperature in ATIG weld is greater comparatively to TIG weld leading to increase the proportion of delta ferrite retained in austenite matrix. On the other hand, in TIG welding, the bead is wide and shallow so the cooling rate is high. As the cooling rate is fast the transformation of delta ferrite to austenite is not completed, resulting on the presence of delta ferrite in the weld bead.

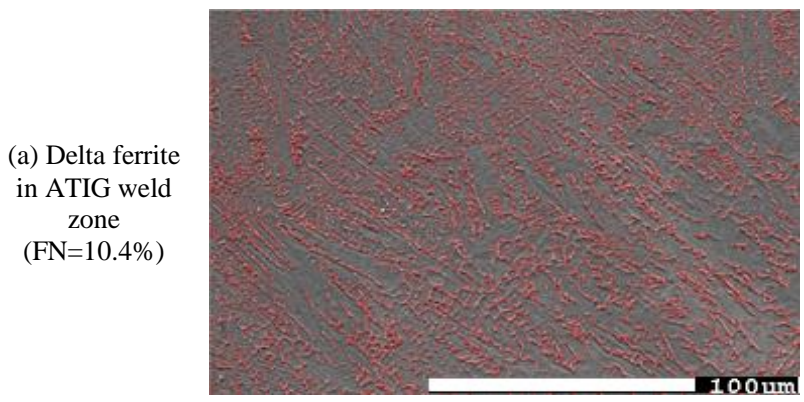

(b) Delta ferrite in TIG weld zone $(\mathrm{FN}=6.8 \%)$

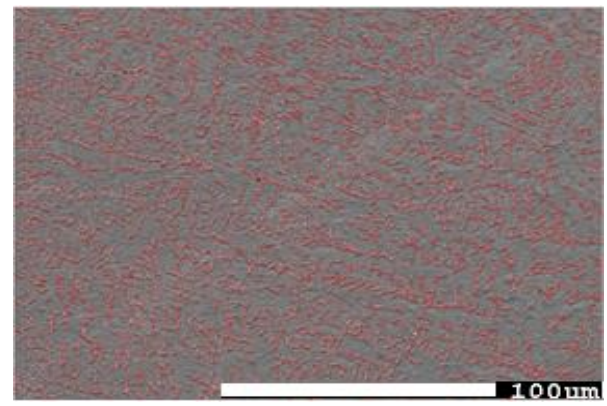

Fig. 20. SEM micrograph of (a) ATIG weld zone and (b) TIG weld zone. Magnification 250X

The ferrite content in heat affected zone is up to $4.6 \%$ in ATIG welding and decreases at $1.4 \%$ in TIG heat affected zone. In TIG, the delta ferrite is randomly distributed in globular form or in small slats as shown in Figure 21(b). However, in ATIG heat affected zone, delta ferrite looks-like elongated inclined stringers as shown in Figure 21(a). 

(a) Delta ferrite in
ATIG HAZ $(\mathrm{FN}=4.6 \%)$
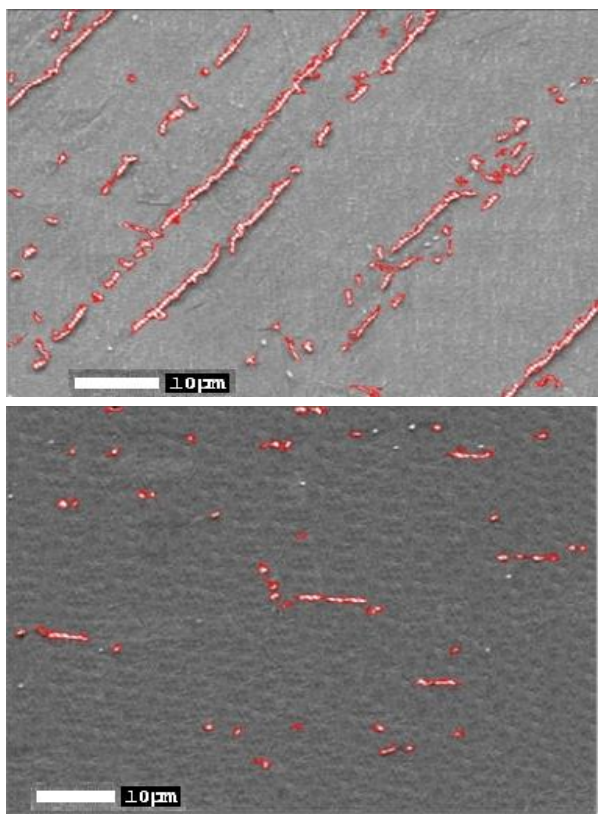

(b) Delta ferrite in TIG HAZ (FN=1.4\%)

Magnification $1000 \mathrm{X}$

\section{CONCLUSION}

This study was conducted on ATIG welding of austenitic 316L. The results are summarized as follows:

- Among 13 oxides tested, $\mathrm{SiO}_{2}, \mathrm{TiO}_{2}$ and $\mathrm{Mn}_{2} \mathrm{O}_{3}$ present the highest depth penetration.

- The optimal flux is composed of $66 \% \mathrm{SiO}_{2}$ and $34 \%$ $\mathrm{Mn}_{2} \mathrm{O}_{3}$.

- The size of ATIG weld bead is bigger than the one of TIG weld bead. The activated flux enhances the heat provided to the weld pool leading to high proportion of retained delta ferrite $(10.4 \%)$. However, TIG weld is wider and shallower so the molten metal cools rapidly in comparison with ATIG molten metal. In the case of TIG weld the transformation of delta ferrite to austenite is stopped earlier due to the fast cooling giving delta ferrite proportions up to $6.8 \%$.

- The hardness HRA property of ATIG weld is improved comparatively to TIG weld. This result is related with the high delta ferrite content in ATIG weld zone.

- EDS/SEM analysis reveals the presence of $\mathrm{FeS}_{2}$, silicon, and oxygen in ATIG welded zone which could be the reason of the decrease of sudden impact load in comparison with TIG weld.

- Mixing design method is the more appropriate tool to get optimal flux composition when depth and $\mathrm{D} / \mathrm{W}$ ratio improvements are desirable. Based on experiments' results, one can say that Minitab software can predict accurately the responses.

\section{ACKNOWLEDGEMENTS}

This work is supported by the Deanship of Scientific Research in Prince Sattam Bin Abdulaziz University, Saudi
Arabia under the research project number 2017/01/7373. Authors acknowledge and thank Dr. Nabeel Alharthi, Director, Centre of Excellence for Research in Engineering Materials for his help in performing SEM/EDS analysis.

\section{REFERENCES}

[1] S. Gurevitch, V. Zamkov, N. Kushnirenko, "Improving the penetration of titanium alloys when they are welded by argon tungsten arc process", Automat Weld, Vol. 18. No. 9, pp. 1-5, 1965

[2] B. Paton, V. Zamkov, V. P. Prilouski, "Le soudage a-tig du titane et de ses alliages", Soudage et Techniques Connexes, Vol. 52, No. 11-12, pp. 23-26, 1998 (in French)

[3] C. Heiple, J. Roper, "Mechanism for minor element effect on GTA fusion zone geometry", Welding Journal, Welding Research Supplement, pp. 97s-102s, 1982

[4] C. R. Heiple, J. R. Roper, R. T. Stagnber, "Surface active element effect on the shape of GTA, laser and electron beam welds", Welding Journal, Vol. 62, No. 3, pp. 72s-77s, 1983

[5] C. R. Heiple, J. R. ROPER, "Effect of SO2 Shielding Gas Addition on GTA Weld Shape Welding”, Welding Research Supplement, pp. 159s$162 \mathrm{~s}, 1985$

[6] P. Burgardt, C. R. Heiple, "Interaction between Impurities and Welding Variables in Determining GTA Weld Shape", Welding Research Supplement, pp. 150-155, 1986

[7] W. Lucas, D. Howse, "Activating flux - increasing the performance and productivity of the TIG and plasma processes", Welding and Metal Fabrication, Vol. 68, No. 2, pp. 7-10, 1996

[8] W. Lucas, D. Howse, M. Savistky, I. Kovalenko, "A-tig flux for increasing the performance and productivity of welding processes", IIW/IIS Budapest Proceedings, IIW Commission XII, Budapest, Romania, 1996

[9] A. G. Simonik, "Effect of contraction of the arc discharge upon the introduction of electro-negative elements", Svar. Proiz., Vol. 3, pp. 4951,1976

[10] S. Sire, S. Marya, "New perspectives in tig welding of aluminium through flux application, FBTIG process", Proceedings. of the 7th International Welding Symposium, Kobe, Japan, pp. 113-118, 2001

[11] S. Sire, S. Marya, "On the development of a new flux bounded tig process (FBTIG) to enhance weld penetrations in aluminium 5086", International Journal of Forming Processes, Vol. 5, pp. 39-51, 2002

[12] S. Sire, S. Marya, "On the selective silica application to improve welding performance of tungsten arc process for a plain carbon steel and aluminium", CR Mecanique - Academie des sciences, Vol. 330, pp. 8389, 2002

[13] R. H. Zhang, D. Fan, "Study activating flux for mild steel", Transactions of the China Welding Institution, Vol. 24, pp. 16-18, 2003

[14] Z. Zhang, L. Dong, M. Li, L. Wang, "Microstruture feature analysis activating TIG weld joint", Transactions of the China Welding Institution, Vol. 25, pp. 55-58, 2004

[15] C. Yang, S. Lin, F. Liu, L. Wu, Q. Zhang, "Research on the mechanism of penetration inccrease by flux in A-TIG welding", Journal of Materials Science and Technology, Vol. 19, pp. 225-227, 2003

[16] C. Dong, S. Katayama, "Basic understanding of A-TIG welding process", IIW Commision XII Workshop, DocXII-1802-04, Osaka, Japan, 2004

[17] C. Yang, S. Lin, F. Liu, L. Wu, Q. Zhang, "Research on the mechanism of penetration inccrease by flux in A-TIG welding", Journal of Materials Science and Technology, Vol. 19, No. 1, pp. 225-227, 2003

[18] H. Y. Huang, "Effects of activating flux on the welded joint characteristics in gas metal arc welding", Materials and Design, Vol. 31, No. 5, pp. 2488-2495, 2010

[19] K. H. Tseng, C. Y. Hsu, "Performance of activated TIG process in austenitic stainless steel welds", Journal of Materials Processing Technology, Vol. 211, No. 3, pp. 503-512, 2011

[20] A. Hdhibi, K. Touileb, R. Djoudjou, A. Ouis, M. L. Bouazizi, J. Chakhari, "Effect of single oxide fluxes on morphology and mechanical 
properties of ATIG on $316 \mathrm{~L}$ austenitic stainless steel welds", Engineering Technology and Applied Science Research, Vol. 8 No. 3, pp. 3064-3072, 2018

[21] M. Zuber, V. Chaudhri, V. K. Suri, S. B. Patil, "Effect of Flux Coated Gas Tungsten Arc Welding on 304L", International Journal of Engineering and Technology, Vol. 6, No. 3, pp. 177-181, 2014

[22] R. Duhan, S. Choudhary, "Effect of different fluxes on hardness and microstructure of ss 304 in GTAW welding", International Journal of Mechanical Engineering, Vol. 3, No. 4, pp. 1-8, 2014

[23] K. H. Tseng, "Development and application of oxide-based flux powder for tungsten inert gas welding of austenitic stainless steels", Powder Technology, Vol. 233, pp. 72-79, 2013

[24] A. B. Patel, S. P. Patel, "The effect of activating fluxes in TIG welding by using Anova for SS 321", International Journal of Engineering Research and Applications, Vol. 4, No. 5, pp. 41-48, 2014

[25] R. Saidov, U. Semmler, K. Matthes, A. Bohr, "Improving the weldability of al alloys by using fluxes - part 2: Microstructures, chemical and mechanical properties and weld preparation", Welding and Cutting, Vol. 5, pp. 282-285, 2003

[26] F. Liu, C. Yang, S. Lin, L. Wu, S. Su, "Effect of weld microstructure on weld properties in A-TIG welding of titanium alloy", Transactions of Nonferrous Metals Society of China (English Edition), Vol. 13, pp. 876880, 2003

[27] M. Marya, "Theoretical and experimental assessment of chloride effects in the A-TIG welding of magnesium", Welding in the World, Vol. 46, No. 7-8, pp. 7-21, 2002

[28] P. Modenesi, E. Apolinario, I. Pereira, "TIG welding with singlecomponent fluxes", Journal of Materials Processing Technology, Vol. 99, No. 1-3, pp. 260-265, 2000

[29] S. Sire, S. Marya, "New perspectives in tig welding of aluminium through flux application, FBTIG process", in: Proceedings of the 7th International Welding Symposium, pp. 113-118, Japan Welding Society, 2001

[30] S. Choudhary, E. Duhanb, "Effect of Activated Flux on Properties of SS 304 Using TIG Welding", IJE Transactions B: Applications Vol. 28, No. 2, pp. $290-295,2015$

[31] K. H. Tseng, C. Y. Hsu, "Performance of activated TIG process in austenitic stainless steel welds", Journal of Materials Processing Technology, Vol. 211, pp. 503-512, 2011

[32] K. D. Ramkumar, D. Mishra, G. Thiruvengatam, S. P. Sudharsan, T. H. Mohan, V. Saxena, R. Pandey, N. Arivazhagan, "Investigations on the microstructure and mechanical properties of multi-pass PCGTA welding of super-duplex stainless steel", Bulletin of Materials Science, Vol. 38, No. 4, pp. 837-846, 2015

[33] H. I. Kurt, R. Samur, "Study on microstructure, tensile test and hardness 304 stainless steel jointed by TIG welding", International Journal of Science and Technology, Vol. 2 No. 2, pp. 163-168, 2013 